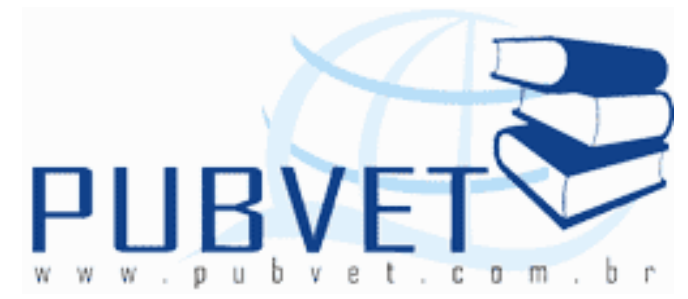

PUBVET, Publicações em Medicina Veterinária e Zootecnia.

\title{
Processamento, pasteurização, desidratação e outros processos similares de conservação de ovos de consumo
}

\author{
Fernanda Lima Cunha ${ }^{1 *}$; Flávia Aline Andrade Calixto ${ }^{1}$; Carla da Silva \\ Carneiro ${ }^{1}$; Kênia de Fátima Carrijo ${ }^{2}$
}

${ }^{1}$ Doutorandas do Programa de Pós Graduação em Higiene Veterinária e Processamento Tecnológico de Produtos de Origem Animal. Faculdade de Veterinária. Universidade Federal Fluminense (UFF). *Autor para contato: Fernanda Lima Cunha. Endereço: Rua Vital Brazil Filho, 64, Santa Rosa, CEP: 24.230-340. Niterói-RJ, Brasil. Email: nandavetuff@yahoo.com.br.

${ }^{2}$ Docente da Faculdade de Medicina Veterinária, Universidade Federal de Uberlândia (UFU), Uberlândia-MG, Brasil.

\section{Resumo}

Os produtos derivados de ovos são preparados a partir de ovos inteiros, da clara ou da gema separadamente. São utilizados como produtos líquidos, congelados ou desidratados, principalmente na indústria de sobremesas e panificação, na elaboração de massas alimentícias, maioneses, sopas em pó, cremes, etc. A utilidade dos produtos do ovo em grande quantidade de alimentos deve-se à sua coagulabilidade por ação do calor, por sua capacidade formadora de espuma e por sua ação emulsificante, além da cor e do aroma que conferem. A pasteurização, desidratação e tecnologias emergentes, são grandes aliadas à fabricação industrial e uniformização dos produtos, sendo 
atualmente o maior mercado consumidor. Porém, técnicas emergentes na indústria de ovos devem ser melhores estudadas para ser considerada como um processamento de sucesso e seja produzido em escala comercial disponibilizando estas vantagens e segurança não somente na indústria, mas também nos supermercados, favorecendo o alcance do consumidor. $O$ objetivo deste trabalho foi fazer uma explanação sobre os processos tecnológicos de pasteurização, desidratação entre outros por meio de uma revisão de literatura, além de esclarecer os efeitos dos processos de conservação dos ovos, na qualidade e no prazo comercial além de salientar as vantagens para sua utilização.

Palavras-chave: ovos, pasteurização, desidratação, conservação.

\title{
Processing, pasteurization, dehydration and other similar processes of conservation of eggs of consumption
}

\begin{abstract}
The egg products are prepared from whole eggs, yolks of clear or separately, are used as liquid, frozen or dehydrated, especially in desserts and baking industry, in the preparation of pasta, mayonnaise, powdered soups, creams, etc. The usefulness of egg products in large quantities of food due to its coagulation by the action of heat, foam-forming ability and its emulsifying action beyond the color and aroma to match. The pasteurization, dehydration and emerging technologies are powerful allies for the industrial manufacture and standardization of products, currently the largest consumer market. However, emerging techniques in the industry best studied eggs should be considered to be a successful processing and is produced on a commercial scale and providing these advantages not only in the security industry but also in supermarkets to reach the consumer. The aim was to make an explanation of the technological processes of pasteurization, dehydration among others by means of a literature review to clarify the effects of processes of preservation
\end{abstract}


of eggs, quality and within business as well as highlighting the advantages for their use.

Keywords: eggs, pasteurization, dehydration, conservation

\section{INTRODUÇÃO}

O ovo é utilizado com muita frequência pela população brasileira, pois, além de apresentar preços acessíveis, faz parte do seu hábito alimentar. Tratase de um alimento que é fonte de proteínas de alto valor biológico e sua gema é rica em vitamina A (RODRIGUES, 2001).

O ovo já foi tido como um dos melhores alimentos para o homem. Porém, nas décadas 80 e 90, foi literalmente banido dos cardápios saudáveis. Hoje está reabilitado, baseado em estudos cautelosos focados à saúde. Pesquisas constataram que não existem vínculos entre o consumo de ovos e o aumento do nível de colesterol no organismo, mal que denegriu a imagem desse alimento por anos. O ovo é rico em proteínas e balanceado em termos de calorias, aminoácidos e vitaminas (AVISITE, 2009).

A produção brasileira de ovos em 2008 aumentou 5,3\%, o que significou volume de 2,281 bilhões de dúzias - 27,368 bilhões de unidades (IBGE, 2009). Mas esse número não corresponde à produção total do país, já que informações levantadas são de estabelecimentos com plantel de, no mínimo, 10 mil galinhas poedeiras. Assim, a produção efetiva brasileira é maior que a apontada. O crescimento da produção e da qualidade do produto habilitam o Brasil para um mercado gigantesco para ovos e derivados de ovos frescos e processados.

Os produtos derivados de ovos são preparados a partir de ovos inteiros, da clara ou da gema separadamente. São utilizados como produtos líquidos, congelados ou desidratados, principalmente na indústria de sobremesas e panificação, na elaboração de massas alimentícias, maioneses, sopas em pó, cremes, etc. A utilidade dos produtos do ovo em grande quantidade de alimentos deve-se a sua coagulabilidade por ação do calor, por sua capacidade 
formadora de espuma e por sua ação emulsificante, além da cor e do aroma que conferem (ORDOÑEZ, 2005b).

Segundo Maggi (s/d) a industrialização de ovos aumenta a segurança bacteriológica (por submeter-se a um processo de pasteurização). Facilita o uso e a dosagem da quantidade utilizada. Requer simples manuseio, proporcionando economia de tempo e mão de obra. Facilita a distribuição e o comércio internacional na indústria de alimentos.

A pasteurização destes produtos de ovos objetiva assegurar a ausência de qualquer bactéria patogênica nos produtos de ovos (CUNNINGHAM, 1995).

A eliminação de parte da água presente no ovo reduz o volume do produto e diminui a atividade de água, assim estes produtos possuem vantagens sobre outros derivados de ovos. O produto da desidratação pode ser armazenado em temperaturas ambientes; o custo de armazenamento e transporte é menor; são produtos homogêneos e de fácil utilização; permite um controle preciso da quantidade de água adicionada a um produto ou utilizado na forma seca (ORDÓÑEZ et al., 2005a).

O objetivo deste trabalho foi fazer uma explanação sobre os processos tecnológicos de pasteurização, desidratação entre outros, por meio de uma revisão de literatura a fim de esclarecer os efeitos dos processos de conservação dos ovos, na qualidade e no prazo comercial além de salientar as vantagens para sua utilização.

\section{REVISÃO BIBLIOGRÁFICA}

\subsection{ESTABELECIMENTOS DE OVOS E DERIVADOS}

Segundo Brasil (2008) os estabelecimentos de ovos e derivados são classificados em:

1. Entrepostos de ovos: são os estabelecimento destinados ao recebimento, classificação, acondicionamento, identificação e distribuição de ovos em natureza, dispondo ou não de instalações para sua industrialização. 
2. Fábrica de conservas de ovos: é o estabelecimento destinado ao recebimento e à industrialização de ovos.

\subsection{DEFINIÇÕES}

Conforme as Normas Gerais de Inspeção de Ovos e Derivados (BRASIL, 1990), na comercialização de ovos são adotadas as seguintes denominações:

- Ovo Fresco: entende-se o ovo em casca que não foi conservado por qualquer processo e se enquadre na classificação estabelecida. Este ovo perderá sua denominação de fresco se for submetido intencionalmente a temperaturas inferiores a $8^{\circ} \mathrm{C}$, visto que a temperatura recomendada para armazenamento do ovo fresco está entre $8^{\circ} \mathrm{C}$ e $15^{\circ} \mathrm{C}$ com uma umidade relativa do ar entre $70 \%-90 \%$.

- Ovo Frigorificado: refere-se ao ovo em casca conservado pelo frio industrial em temperatura de 0 a $1^{\circ} \mathrm{C}$ em câmara com circulação de ar com grau higrométrico apropriado e de preferência com gás inerte.

- Conserva de Ovos: é o produto resultante do tratamento do ovo sem casca ou partes do ovo, gema ou clara, que tenham sido pasteurizados, resfriados, congelados, adoçados, salgados, desidratados ou liofilizados.

\subsection{PROCESSAMENTO}

A seguir será descrito o fluxograma de processamento de ovos, desde a recepção até a embalagem, conforme ilustrado na Figura 1. 


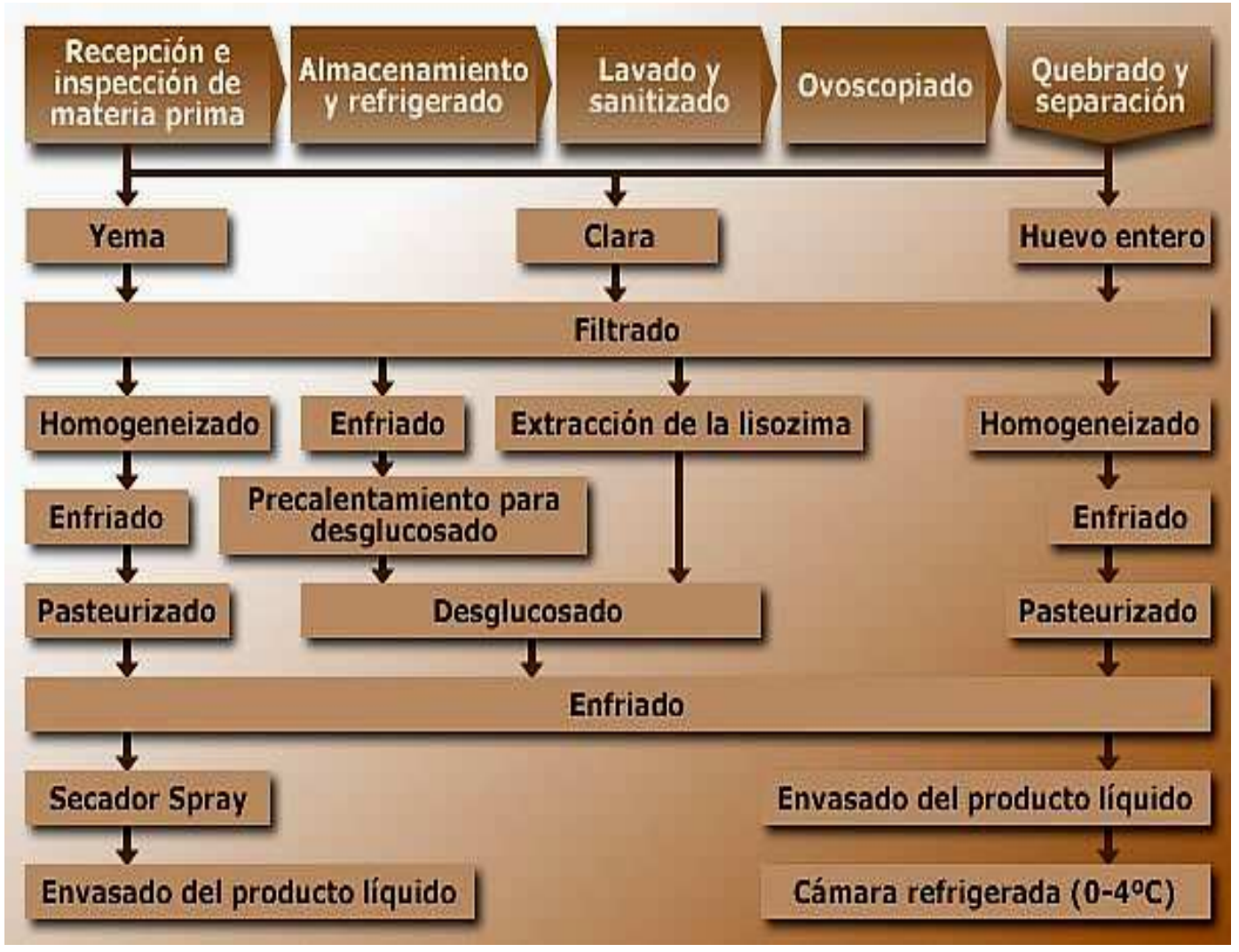

Figura 1. Esquema do processamento de ovos.

Fonte:http://www.alimentosargentinos.gov.ar/03/revistas/r_42/cadenas/Carne s_Huevos_derivados.htm

\subsubsection{Recepção}

A Recepção dos ovos deve ser isolada da área de processamento, com ventilação e iluminação adequadas. A carga é disposta em forma de "pallets", facilitando a operação. O controle de qualidade é realizado através de amostragem, realizada através de testes rápidos para certificar a qualidade dos ovos (MANO et al., 2006).

\subsubsection{Lavagem}

A etapa de Lavagem é realizada dispondo os ovos em esteira rolante, os quais passarão por chuveiros para aspersão de água, com no máximo 50 ppm 
de cloro. Uma concentração acima deste valor pode causar esverdeamento da casca. A temperatura deve ser até $10^{\circ} \mathrm{C}$ acima da temperatura do ovo. Em temperaturas superiores ocorre a expansão do conteúdo do ovo podendo haver o trincamento da casca, e abaixo de $30^{\circ} \mathrm{C}$, existe a contração do conteúdo do ovo podendo ocorrer aspiração de água através dos poros. Após esta etapa os ovos são secos com ar forçado a $30-35^{\circ} \mathrm{C}$ (MANO et al., 2006).

\subsubsection{Ovoscopia}

$\mathrm{Na}$ ovoscopia revela-se a condição da casca do ovo, bem como o seu aspecto interno através de um foco de luz incidente sobre os ovos em movimento de rotação, mantendo-os em um local escuro para perfeita visualização (BRASIL, 1990). Esta etapa é realizada em câmara ovoscópica, sendo eliminadas as unidades fora do padrão aceitável (manchas de sangue ou carne, embrião, gema rompida, casca trincada ou quebrada, ovos sem trasparência) (MANO et al., 2006).

\subsubsection{Quebra e Mistura}

Posteriormente à ovoscopia é realizada a quebra dos ovos, em sala climatizada com temperatura máxima de $16^{\circ} \mathrm{C}$ e ventilação com ar filtrado. Pode ser manual ou mecânica. Pode haver a separação de gema e clara ou processamento do ovo integral. $\mathrm{Na}$ industrialização, essa operação é considerada um ponto crítico. Após a quebra os ovos são filtrados com a finalidade da retenção das calazas, membrana vitelina e fragmentos de casca (MANO et al., 2006).

Em seguida a matéria-prima segue para os tanques de retenção que devem possuir termômetros e agitadores com temperatura de 2 a $5^{\circ} \mathrm{C}$. Nesses tanques ocorre, se necessário, a adição de aditivos: sal ou açúcar (gema destinada ao congelamento), ácido cítrico ou ácido lático (clara). Em sequência 
as claras e gemas seguem para o tanque misturador, caso se queira proporções diferentes de clara e gema (MANO et al., 2006).

\subsubsection{Pasteurização}

Segundo Jay (2005) a pasteurização mediante o uso de calor implica na destruição de todos os microrganismos patogênicos, assim como na destruição ou redução daqueles que provocam a deterioração.

A pasteurização deverá iniciar-se o mais rapidamente possível após a quebra dos ovos, para impedir a deterioração do produto, recomendando-se no período máximo de 72 horas a partir da quebra, desde que mantidos em resfriamento $2^{\circ}$ a $5^{\circ} \mathrm{C}$ (BRASIL, 1990).

Cunningham (1995) salienta que o objetivo deste processo nos produtos de ovos inicialmente foi assegurar a ausência de qualquer bactéria patogênica nos produtos de ovos.

A temperatura máxima que pode ser aplicada ao ovo é limitada pela coagulação da clara. Por isso os tratamentos mais rígidos são empregados em ovos inteiros e em gemas, os mais suaves, em claras. As combinações tempo e temperatura necessárias para a destruição dos microrganismos, fundamentalmente Salmonella, são ou se aproximam muito das que afetam negativamente as propriedades físicas e funcionais desses produtos (ORDÓÑEZ, 2005b).

Segundo Brasil (1990) os pasteurizadores terão de ser de placas e possuir painel de controle, com termo-registrador automático, termômetro e válvula automática de desvio de fluxo em perfeito estado de funcionamento. A pasteurização dos produtos líquídos de ovos deverá ser sob condições e requisitos definidos de tempo/temperatura ajustados às características de cada produto a ser processado. Recomenda-se os seguintes valores: de $60^{\circ} \mathrm{C} / 3,5$ minutos para Ovo integral, os valores de $61^{\circ} \mathrm{C} / 3,5 \mathrm{~min}$ para gema e os valores de $57^{\circ} \mathrm{C} / 3,5$ minutos para clara. 
A atividade da enzima catalase na clara e no ovo integral é substancialmente destruída a $54,5^{\circ} \mathrm{C}$, sendo, portanto, a enzima de eleição no estudo da eficiência da pasteurização, tanto no ovo integral, como na gema e clara pasteurizadas (MANO et al., 2006).

A adição de $\mathrm{NaCl}$ e de sacarose permite aplicar temperaturas de até 66 a $67^{\circ} \mathrm{C}$ se elevadas a $\mathrm{pH}$ 7. As proteínas da clara ficam mais estáveis e não sofrem mudanças em suas propriedades funcionais após o processo de pasteurização (ORDÓÑEZ, 2005b).

Para evitar a perda do valor nutritivo e funcionalidade dos ovos inteiros, desenvolveu-se recentemente, um tratamento de ultrapasteurização de ovos líquidos, utilizando binômios tempo / temperatura que oscilam entre 60 e $72^{\circ} \mathrm{C}$ e 30 e 95 segundos. Há muitas combinações possíveis, mas parece que o tratamento a $68^{\circ} \mathrm{C}$ durante 60 segundos assegura boa vida útil ao produto sem perder significantemente sua funcionalidade durante um período superior a quatro semanas. O acondicionamento asséptico desse produto consegue prolongar o prazo comercial inclusive por até seis meses (ORDÓÑEZ, 2005b).

Schuman et al. (1997) avaliaram o potencial de inativação da Salmonella Enteritidis a $57^{\circ} \mathrm{C}$ e $58^{\circ} \mathrm{C}$ por imersão em água e os efeitos deste tratamento com relação a funcionalidade do albúmen e atributos de qualidade interna dos ovos, e obtiveram bons resultados.

Carvalho et al. (2005) verificaram que a pasteurização de ovos em casca por imersão em água com agitação, mantendo-se a temperatura de $57^{\circ} \mathrm{C}$ por 20 minutos é efetivo na destruição de Salmonella Enteritidis.

\subsubsection{Embalagem}

Os produtos podem ser acondicionados em embalagens de polietileno, baldes plásticos, embalagens UHT (figura 2) ou caminhões-tanque (2 a $5^{\circ} \mathrm{C}$ ), sendo esta etapa também considerada como um ponto crítico (MANO et al., 2006). 

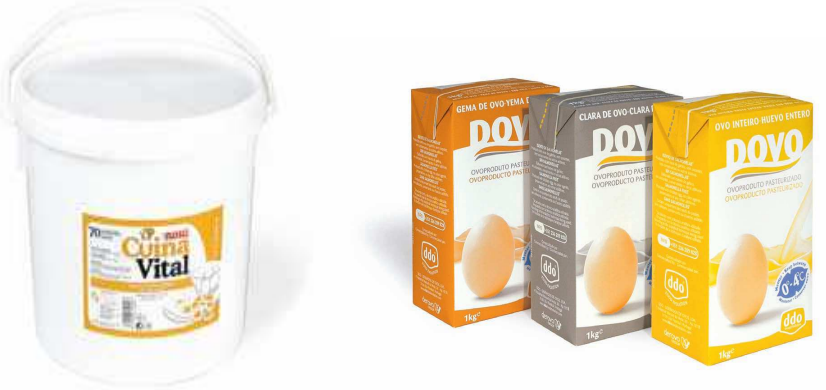

Figura 2 - Embalagens usadas para acondicionamento de ovos

Fonte: Boletim Informativo Derovo, Ano 11, no 1, fev. 2008.

\subsubsection{Resfriamento, Congelamento e Descongelamento}

A temperatura de resfriamento é de normalmente $0^{\circ} \mathrm{C}$.

O congelamento de produtos derivados do ovo é um dos processos mais utilizados hoje para sua conservação. Pode-se congelar o ovo inteiro, a gema ou a clara separadamente, assim como misturas entre eles e outros ingredientes, como sal e sacarose, principalmente. Costuma-se realizar o congelamento em congeladores de placas entre -23 e $-25^{\circ} \mathrm{C}$, podendo-se conservar até 10 meses a temperaturas de -15 a $-18^{\circ} \mathrm{C}$ (ORDÓÑEZ, 2005b).

As propriedades funcionais da clara de ovo não sofrem mudanças significativas quando submetidas ao processo de congelamento desde que se realize congelamento rápido para evitar a presença de cristais grandes. Pra se evitar esse processo costuma-se acrescentar hexametafosfato sódico e citrato trissódico, capazes de formar uma rede entre as proteínas que as torna menos sensíveis ao estresse do congelamento e descongelamento (ORDÓÑEZ, 2005b).

Quando se congelam as gemas separadamente observa-se um aumento da viscosidade e um decréscimo da solubilidade do produto descongelado. Para evitar isso, homogeneízam-se-as e, acrescenta-se $\mathrm{NaCl}$ (2 a $10 \%$ ) ou sacarose (8 a $10 \%$ ). A ação protetora do sal e da sacarose baseia-se, provavelmente na queda do ponto de congelamento (ORDÓÑEZ, 2005b). 
O descongelamento é realizado em câmaras a $2-3^{\circ} \mathrm{C}$, no qual o produto final deve apresentar no máximo $10^{\circ} \mathrm{C}$.

\subsection{OUTROS PROCESSOS}

\subsubsection{Pasteurização por Irradiação}

A irradiação de alimentos é um método de conservação sem alteração significativa da temperatura do produto. Consiste no emprego de radiação ionizante como energia suficiente para ionizar e excitar átomos ou moléculas (efeito primário) e permite a recombinação da matéria em radicais livres (efeitos secundários) e biologicamente a energia altera o material genético (RNA ou DNA) levando a danos irreversíveis dos organismos. Através da morte celular e alterações da matéria os produtos têm um prolongamento da validade comercial (FELLOWS, 2006; ORDÓÑEZ et al., 2005a).

A principal fonte de irradiação é radiação gama por cobalto-60. Os produtos podem ser irradiados já embalados, o que evita recontaminação após o processamento. Quando a fonte é exposta e os íons reativos entram em contato com o alimento, estes danificam ou destroem os microrganismos (FELLOWS, 2006). O efeito letal da radiação ionizante deve-se, primeiramente, aos danos causados no DNA e RNA. Essas alterações afetam a expressão de alguns genes e a biossíntese de várias enzimas, além de interferir na divisão celular. Com isso, há uma redução de maneira logarítmica do número de micro-organismos deteriorantes e eliminação de patógenos, com destaque para Salmonella sp., no produto levando a uma pasteurização "a frio". A Salmonella oranienburg a temperatura de tratamento do ovo a $0^{\circ} \mathrm{C}$ é eliminada em dose de 0,32 kGy (ORDÓÑEZ et al., 2005a).

A radiação gama por cobalto-60 em ovos líquidos congelados pode ser usada em baixas doses com a finalidade de pasteurização (KIJOWSKI et al., 1994). Esse processo elimina a contaminação por Enterobacteriaceae, com especial atenção para Salmonella sp (KIJOWSKI et al., 1994). 
O processo é feito em irradiador próprio de maneira contínua conforme pode ser observado na Figura 3.

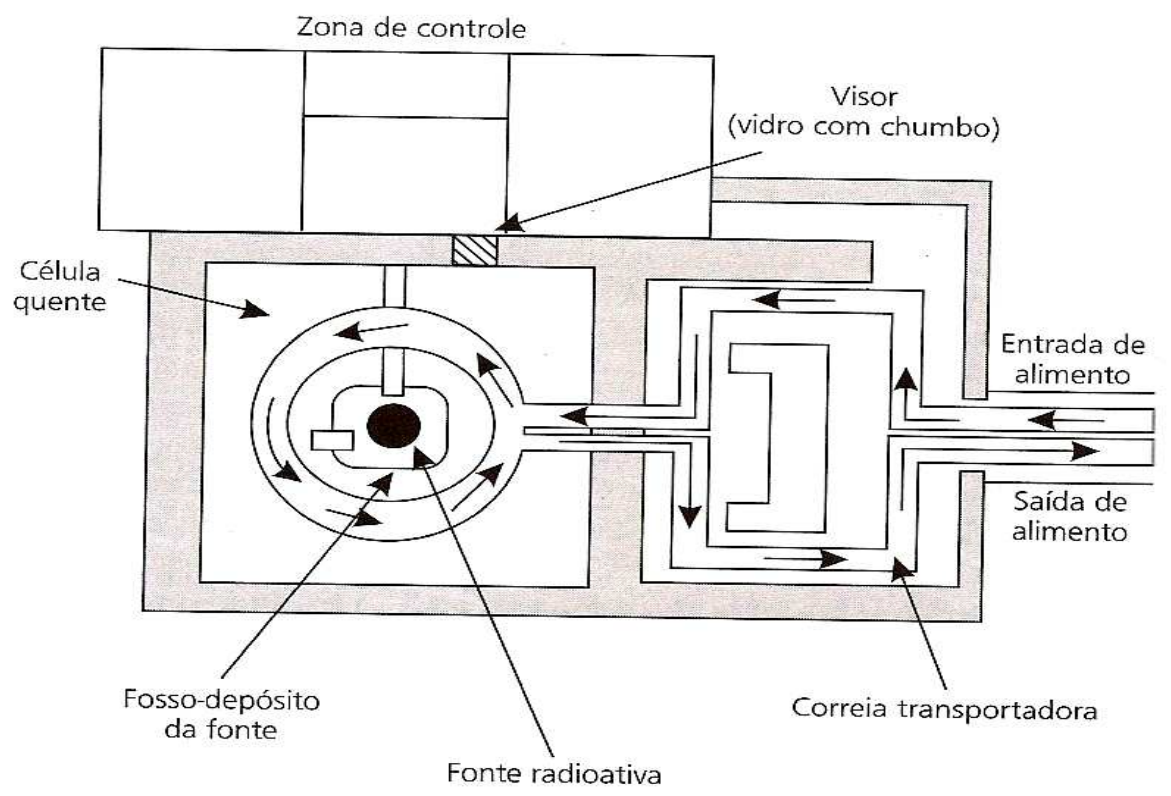

Figura 3: Processamento por radiação gama.

Fonte: Ordóñez et al., 2005a.

O efeito da radiação sobre o alimento depende de alguns fatores. Alguns deles são dependentes dos microrganismos como: o tipo (as bactérias Gram positivas são mais resistentes, assim como as formadoras de esporos); a carga microbiana (que influencia da mesma maneira que tratamentos térmicos pelo decaimento logarítmico); a idade dos microrganismos (as bactérias são mais resistentes em fase lag já que não estão multiplicando o material genético); a composição do alimento (quanto mais complexo, maior a resistência); a ausência de oxigênio (que favorece a resistência porque diminui o efeito secundário da mesma maneira que o congelamento sobre a água líquida) (JAY, 2005).

Apesar de a irradiação permitir a seguridade higiênico-sanitária do ovo, o processamento aumenta as mudanças químicas como a oxidação, podendo causar alterações sensoriais. Pode-se destacar a oxidação lipídica em ovos inteiros ou gemas (KATUIIN-RAIEM,1992). 


\subsubsection{Desidratação}

O ovo é um produto altamente popularizado na alimentação, faz parte do cardápio alimentar até de alguns vegetarianos. Por suas características constitucionais, parte do produto se perde durante o transporte com as quebras da casca. A industrialização deste produto pode diminuir essas perdas em transporte, como a desidratação. O ovo em pó é um dos produtos mais comuns da indústria avícola no mundo. Uma instalação de desidratação de ovos é capaz de produzir 240 toneladas por ano trabalhando 16 horas por dia em 300 dias de trabalho tendo uma ótima produtividade. No quadro 1 encontram-se os equipamentos básicos necessários para esta produção (GLOBAL AGRISYSTEM, 2009).

O uso de produtos derivados do ovo, como líquido ou desidratado é direcionado principalmente para indústrias de sobremesas e panificação, na elaboração de massas, maioneses, sopas em pó, margarina e cremes. 0 amplo uso na indústria alimentícia deve-se principalmente ao poder emulsificante do ovo. Este possui, também, coagulabilidade por ação do calor, capacidade formadora de espuma, além de conferir cor e aroma específicos (ORDÓÑEZ et al., 2005a).

A eliminação de parte da água presente no ovo reduz o volume do produto e diminui a atividade de água. Assim estes produtos possuem vantagens sobre outros derivados de ovos. O produto da desidratação pode ser armazenado em temperatura ambiente; o custo de armazenamento e transporte é menor; são produtos homogêneos e de fácil utilização; permitem um controle preciso da quantidade de água adicionada a um produto ou utilizado na forma seca (ORDÓÑEZ et al., 2005a).

\subsubsection{Desidratação por "Spray Dryer"}

O processo tecnológico consiste da quebra do ovo seguida de filtração, pasteurização, desidratação por "spray dryer", embalagem e estocagem. A 
estocagem deve ser feita em ambiente escuro e seco com umidade relativa igual ou menor que $75 \%$, temperatura de 8 a $22^{\circ} \mathrm{C}$ sem flutuações maiores que $4^{\circ} \mathrm{C}$ ao dia. Quando a desidratação é feita em parte do ovo, gema ou clara há uma etapa de separação após a quebra. A indústria de processamento de ovos também processa produtos diferenciados como ovo integral ou clara desidratados desaçucarados. Neste caso após a quebra é realizada uma separação branca, filtração e retirada do açúcar. Depois o processamento é igual aos anteriores (OVOVITA, 2009).

O processo de eliminação de açúcares no ovo tem como finalidade evitar o escurecimento não-enzimático (Reação de Maillard) que podem surgir durante o tratamento térmico e armazenamento de produtos derivados de ovos (ORDÓÑEZ et al., 2005a).

A retirada do açúcar pode ser realizada por duas técnicas: fermentação microbiana ou processo enzimático. Na fermentação microbiana, gêneros como Lactobacillus e Enterobacter ou levedura da espécie Saccharomyces cerevisiae são utilizados para fermentar a glicose com formação de ácido glicônico. A ação da levedura sobre os açúcares da clara é mais rápida do que as bactérias. Para melhor desenvolvimento desses microrganismos, adiciona-se ácido cítrico ou lático ajustando o pH entre 7 e 7,5. Em gemas, a fermentação pode provocar ligeiras alterações de sabor. 0 processo enzimático é realizado por ação de duas enzimas (glicose-oxidase e catalase) auxiliada por adição de peróxido de hidrogênio. A vantagem do uso de enzimas é que não altera o sabor do produto, porém é um método mais caro e com formação de espuma pela adição do peróxido de hidrogênio (ORDÓÑEZ et al., 2005a).

A estrutura e os equipamentos de uma indústria de desidratação de ovos são relativamente simples. No quadro 1 estão listados os equipamentos básicos para seu funcionamento. 
Quadro 1: Equipamentos básicos de uma instalação de desidratação de ovos.

\begin{tabular}{|l|c|}
\hline EQUIPAMENTOS & QUANTIDADE \\
\hline Quebrador de ovos & 4 \\
\hline Centrífuga & 2 \\
\hline Filtro & 2 \\
\hline Tanque de estocagem & 4 \\
\hline Bomba de alimentação & 4 \\
\hline Aquecedores tubulares & 4 \\
\hline Tanque de equilíbrio & 2 \\
\hline Bomba de alta pressão & 1 \\
\hline "Spray dryer" sob alta pressão & 1 \\
\hline $\begin{array}{l}\text { Ciclone com exaustão e } \\
\text { ventilação }\end{array}$ & 1 \\
\hline Unidade empacotadora & \\
\hline
\end{tabular}

Fonte: Global AgriSystem, 2009.

Usado para alimentos líquidos, o "spray dryer" (Figura 4) funciona fazendo com que pequenas gotículas sejam aspergidas dentro de uma corrente de ar quente a 150 a $300^{\circ} \mathrm{C}$ em câmara de secagem. A evaporação da água das gotas de alimentos ocorre em segundos e cada gotícula se transforma em uma partícula seca. Apesar de usar altas temperaturas não há um superaquecimento do produto, pois, normalmente, a temperatura da superfície do alimento não se eleva tanto, a própria evaporação da água está associada ao resfriamento na câmara.

O equipamento necessita de alguns elementos essenciais: câmara de secagem e um sistema de recolhimento de partículas secas; ventiladores e aquecedores de ar. Na câmara de secagem, as gotículas dispersas entram em contato com ar quente o suficiente para a desidratação. A entrada na câmara do ar quente e do alimento pode ser junta ou separada. A partícula pode decair reta ou em espiral no aparelho; a última trajetória é mais longa por isso mais 
eficiente. As partículas secas vão para o fundo do aparelho, enquanto que o vapor da evaporação sai da câmara por saída mais superior (FELLOWS, 2006; ORDÓÑEZ et al., 2005a).

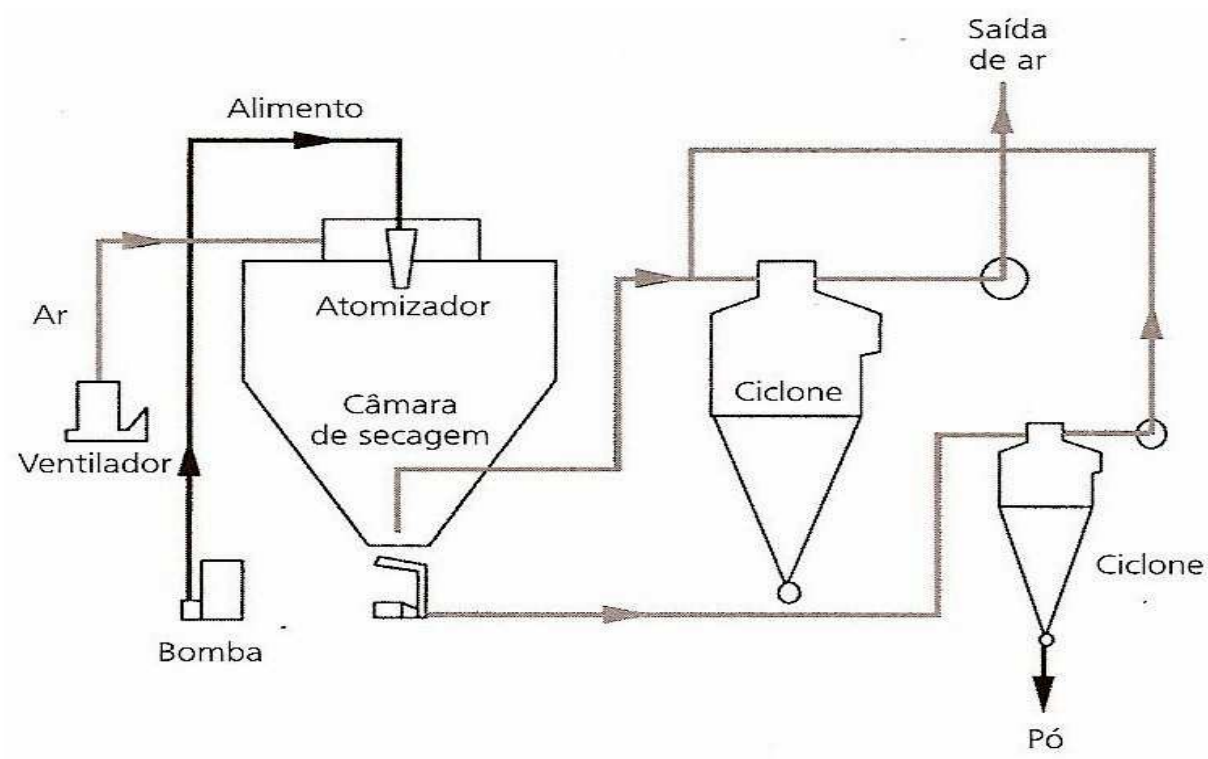

Figura 4: Desenho esquemático de um "spray dryer".

Fonte: Ordóñez et al., 2005a.

Os produtos que normalmente são desidratados com esta técnica são líquidos ou massas com viscosidades adequadas para serem atomizados como produtos de ovos (ORDÓÑEZ et al., 2005a).

O processo de desidratação de ovos pode ser representado no fluxograma a seguir (Figura 5): 


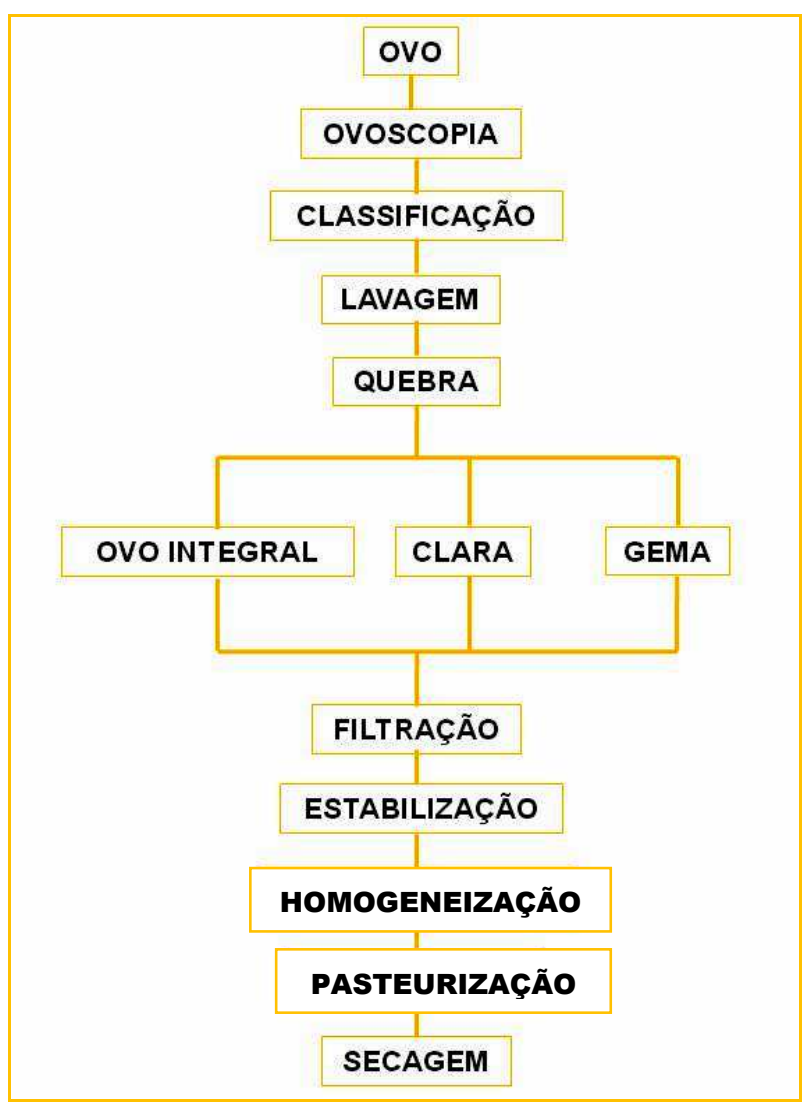

Figura 5: Processamento de desidratação de produtos de ovos.

Em relação às características do produto, o ovo integral desidratado possui como parâmetros físico-químicos: $\mathrm{pH}$ - 7,5 a 9,5; umidade- 2 a 5\%; gordura - 61 a $68 \%$; solubilidade de 85 a 95\%; e como informação nutricional para $100 \mathrm{~g}$ do produto possui valor calórico de $580 \mathrm{kcal} ; 5 \mathrm{~g}$ de carboidrato, $46 \mathrm{~g}$ de proteína, $42 \mathrm{~g}$ de gorduras totais, $19 \mathrm{~g}$ de gorduras saturadas e $0 \mathrm{~g}$ de gorduras trans e fibras alimentares. Com algumas diferenças a gema desidratada possui os seguintes parâmetros físico-químicos: $\mathrm{pH} 6,0$ a 7,0; umidade 2 a 5\%; e gordura 61 a 68\%; solubilidade de 85 a 90\%. A informação nutricional para uma porção de $100 \mathrm{~g}$ do produto é de $690 \mathrm{kcal}$ de valor energético; $0,5 \mathrm{~g}$ de carboidrato; $31 \mathrm{~g}$ de proteína; $64 \mathrm{~g}$ de gorduras totais; $19 \mathrm{~g}$ de gorduras saturadas e $0 \mathrm{~g}$ de gorduras trans e fibras alimentares. A clara desidratada possui $\mathrm{pH}$ entre 6,0 e 8,0; umidade entre 5 e 8\%; percentual de gordura pouco significativo (inferior a 1\%); e solubilidade de 92 a $95 \%$. O valor nutricional deste produto é de $370 \mathrm{kcal}$ de valor energético; $8 \mathrm{~g}$ 
de carboidrato; $85 \mathrm{~g}$ de proteína; $0,3 \mathrm{~g}$ de gorduras totais; e $0 \mathrm{~g}$ de gorduras trans e fibras alimentares, (NATUROVOS, 2009; OVOVITA, 2009).

Em relação às características sensoriais pode-se citar que é uma substância seca homogênea de coloração amarela escura brilhante, com natural odor e sabor adequado a essência do ovo (OVOVITA, 2009).

O produto desidratado deve ser adicionado preferencialmente aos ingredientes secos (NATUROVOS, 2009) nas misturas industriais ou serviços de alimentação e serem reidratados posteriormente.

A equivalência do ovo desidratado reconstituído é de $250 \mathrm{~g}$ de ovo em pó para $750 \mathrm{~mL}$ de água que representa 20 ovos inteiros (OVOVITA, 2009).

$\mathrm{O}$ uso de ovos desidratados ou líquidos em massas alimentícias produz resultados semelhantes ao ovo em casca. Sendo assim, o uso desses produtos é vantajoso pela facilidade de transporte e estocagem, volume ocupado, maior durabilidade e facilidade de mistura à farinha de trigo. A produção de conservas de ovos passou a ser essencial para indústrias de alimentos e serviços de alimentação (ORMENESE et al., 2004).

Ovo inteiro ou gemas desidratadas contém os lipídeos de mais alto poder emulsificante que estão associados com as proteínas e outros componentes da gema (BERGQUIST, 1995).

Para o ovo ser útil na indústria de alimentos, as características nativas do ovo cru devem ser preservadas. Por isso o produto desidratado não é cozido, apenas há uma evaporação da água. O calor usado para a evaporação da água pode ser transmitido por condução ou convecção. O método por "spray dryer" possui rápida evaporação da água (fração de segundos) por possuir uma grande área de superfície de contato entre o produto e o meio aquecido (BERGQUIST, 1995).

Os produtos provenientes da desidratação do ovo, a aplicação dos mesmos e vantagens podem ser visualizados no quadro 2 . 
CUNHA, F.L. et al. Processamento, pasteurização, desidratação e outros processos similares de conservação de ovos de consumo. PUBVET, Londrina, V. 6, N. 31, Ed. 218, Art. 1450, 2012.

Quadro 2: Produtos desidratados de ovos e características.

\begin{tabular}{|c|c|}
\hline Produtos & Características \\
\hline \multirow[b]{2}{*}{$\begin{array}{l}\text { Ovo integral } \\
\text { desidratado }\end{array}$} & $\begin{array}{l}\text { Aplicação: Massas, biscoitos, bolos, pães, pães de queijo, } \\
\text { maioneses, doces, omeletes, tortas, empanados, e outras receitas } \\
\text { em substituição ao ovo in natura. }\end{array}$ \\
\hline & $\begin{array}{l}\text { Vantagens: proporciona estrutura e textura; maior facilidade na } \\
\text { utilização permite a mistura com outros ingredientes secos, tais } \\
\text { como sal, açúcar, farinha; pode ser transportado e estocado a } \\
\text { temperatura ambiente. }\end{array}$ \\
\hline \multirow{2}{*}{$\begin{array}{l}\text { Ovo integral } \\
\text { desidratado Glucosado }\end{array}$} & $\begin{array}{l}\text { Aplicações: é ideal para produção de produtos de panificação, tais } \\
\text { como biscoitos, bolos, bolachas champagne, e outras receitas em } \\
\text { substituição ao ovo in natura. }\end{array}$ \\
\hline & $\begin{array}{l}\text { Vantagens: fornece uma maior aeração à massa resultando em } \\
\text { produto final com melhor textura; pode ser transportado e } \\
\text { estocado a temperatura ambiente. }\end{array}$ \\
\hline \multirow[b]{2}{*}{$\begin{array}{l}\text { Gema de ovo } \\
\text { desidratada }\end{array}$} & $\begin{array}{l}\text { Aplicações: Panetones, waffles, casquinha para sorvete, sorvetes, } \\
\text { biscoitos, bolos de Páscoa, xampus e outras receitas em } \\
\text { substituição a gema de ovo in natura. }\end{array}$ \\
\hline & $\begin{array}{l}\text { Vantagens: adquire-se somente o produto que será utilizado não } \\
\text { gerando subprodutos; maior facilidade na utilização permite a } \\
\text { mistura com outros ingredientes secos, tais como sal, açúcar, } \\
\text { farinha; Pode ser transportado e estocado a temperatura ambiente. }\end{array}$ \\
\hline \multirow[b]{2}{*}{$\begin{array}{l}\text { Gema de ovo } \\
\text { desidratada especial } \\
\text { para maionese }\end{array}$} & $\begin{array}{l}\text { Aplicações: é ideal na produção de maionese e molhos para } \\
\text { salada }\end{array}$ \\
\hline & $\begin{array}{l}\text { Vantagens: fornece uma melhor emulsão e maior consistência à } \\
\text { maionese; maior estabilidade da maionese ao frio e ao calor, } \\
\text { podendo a maionese ser utilizada na elaboração de pratos quentes; } \\
\text { pode ser transportado e estocado a temperatura ambiente. }\end{array}$ \\
\hline \multirow{2}{*}{$\begin{array}{l}\text { Clara de ovo } \\
\text { desidratada - Standard }\end{array}$} & $\begin{array}{l}\text { Aplicações: massas, clarificador de bebidas, merenda escolar, } \\
\text { suplementos alimentares para esportista e gestantes, alimentação } \\
\text { enteral-hiperproteica e outras receitas em substituição a clara in } \\
\text { natura. }\end{array}$ \\
\hline & $\begin{array}{l}\text { Vantagens: excelente fonte de proteína de alta qualidade; } \\
\text { adquire-se somente o produto que será utilizado não gerando } \\
\text { subprodutos; pode ser transportado e estocado a temperatura } \\
\text { ambiente. }\end{array}$ \\
\hline \multirow{2}{*}{$\begin{array}{l}\text { Clara de ovo } \\
\text { desidratada - High } \\
\text { Whip }\end{array}$} & $\begin{array}{l}\text { Aplicações: Suspiros, marshmallow, recheios para chocolates, } \\
\text { coberturas para bolos, doces, torrones, merengues, mousses, } \\
\text { souflês, e outras receitas em substituição a clara in natura. }\end{array}$ \\
\hline & $\begin{array}{l}\text { Vantagens: proporciona maior aeração e textura leve; fornece } \\
\text { maior estabilidade à estrutura da espuma; pode ser transportado e } \\
\text { estocado a temperatura ambiente. }\end{array}$ \\
\hline \multirow[t]{2}{*}{$\begin{array}{l}\text { Clara de ovo } \\
\text { desidratada - High Gel }\end{array}$} & $\begin{array}{l}\text { Aplicações: Massas, coberturas para bolos, doces, torrones, } \\
\text { merengues, mousses, souflês, embutidos, ligante - aglutinante } \\
\text { para hamburgueres e outros produtos a base de carne moída, } \\
\text { peixes, (Kani, Kamaboko) e vegetais, outras receitas em } \\
\text { substituição a clara in natura }\end{array}$ \\
\hline & $\begin{array}{l}\text { Vantagens: elevada força de gel e ação de liga; proporciona } \\
\text { rigidez e estabilidade. }\end{array}$ \\
\hline
\end{tabular}

Fonte: Sohovos, 2009. (http://www.sohovos.com.br/portugues/index.htm) 
Pode-se citar como desvantagem deste método a concentração de colesterol, assim como outros elementos sólidos do ovo; e a oxidação do colesterol durante o processamento podendo gerar elementos com caráter de aterogenicidade como 7-cetocolesterol livre (ESCARABAJAL; TENUTA FILHO, 2005).

\subsubsection{Efeitos da desidratação e estocagem}

Segundo Bergquist (1995) as propriedades funcionais dos ovos são as seguintes: aeração, coagulação, emulsificação; além disso, fornecem odor, cor e sabor característicos.

A aeração é comumente associada à clara e muitos fatores podem ocasionar a perda desta propriedade. Alguns problemas tecnológicos podem ser destacados como: quando na quebra ou separação da clara há mistura com a gema esta propriedade se reduz. Por isso, padroniza-se o máximo de 0,03\% de gema na base líquida da clara. O calor da desidratação também interfere nesta propriedade, principalmente pela ação do calor sobre os açúcares. Alguns métodos de homogeneização também podem alterar esta propriedade por mudança física na estrutura da proteína (BERGQUIST, 1995).

A propriedade coagulante do ovo pode ser alterada em condições severas de desidratação e estocagem inadequada (ibid).

O ovo é um ótimo emulsificante, sendo que a gema possui poder maior que a clara. Esta propriedade se deve, principalmente, às lecitoproteínas. A desidratação, na verdade, aumenta este potencial (ibid).

O sabor e aroma natural do ovo contribuem também para as características dos produtos que o utilizam como ingrediente. A alteração desta característica está relacionada a problemas de desidratação e estocagem principalmente pela reação não enzimática que pode ser evitada com a eliminação do açúcar (ibid). 
As perdas nutricionais são pequenas e pouco significativas quando se submete ao processo de desidratação. A coloração também não é alterada quando o processamento e estocagem são realizados adequadamente (ibid).

Quanto às propriedades físicas, o ovo inteiro ou a gema são mais resistentes ao processamento por "spray dryer" do que a clara. As proteínas da clara são menos termoestáveis podendo gerar coagulação no processamento (ibid).

\subsubsection{Liofilização ou Criodesidratação}

Outro tipo de desidratação de ovos é a tecnologia de liofilização ou criodesidratação. Esse processamento consiste no congelamento rápido $\left(-50^{\circ} \mathrm{C}\right.$ a $-60^{\circ} \mathrm{C}$ ) do ovo líquido ou parte deste previamente pasteurizado e posterior desidratação por sublimação. As características de produto são umidade em torno de 3\%, teor de proteína de $47 \%$, de gordura 37\% e cinzas 3\% (MANO et al., 2006).

Como a água do produto em sua maioria está em estado sólido passando diretamente para o estado gasoso na saída do alimento e as temperaturas de processamento são mais suaves, as modificações por desidratação nos alimentos neste caso são mínimas (ORDOÑEZ et al., 2005b).

Os elementos básicos de um liofilizador são: uma câmara de vácuo, uma fonte de calor, um condensador e uma bomba a vácuo (FIGURA 6). A câmara a vácuo suporta as diferenças de pressão e a bomba mantém esta diferença. A fonte de calor denomina o tipo de liofilizador utilizado, e é quem produz energia para evaporação do gelo. O condensador retém a umidade saída do alimento evitando que ela aumente a umidade dentro da câmara e volte ao alimento (ORDOÑEZ et al., 2005a). 


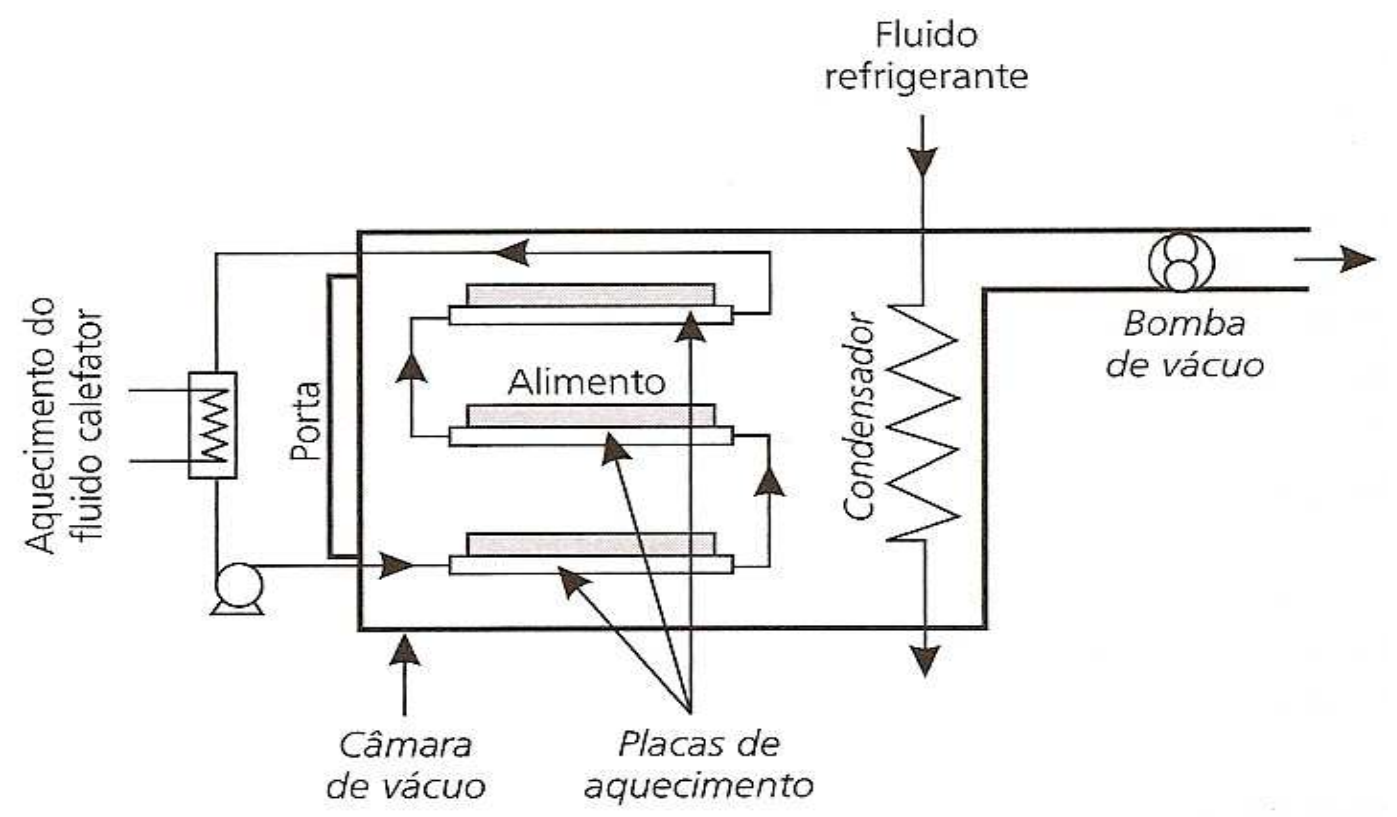

Figura 6: Principais componentes do liofilizador.

Fonte: Ordóñez et al., 2005a.

\subsubsection{Conservação por Secagem}

Os microrganismos necessitam de um teor mínimo de água para o crescimento. Geralmente, bactérias são mais exigentes quanto ao teor de água que leveduras e fungos. Por isso em alimentos secos é mais provável a presença de fungos. Esta dinâmica está relacionada com a atividade de água $\left(a_{w}\right)$ (teor de água livre do alimento). A $a_{w}$ máxima é a da água pura de 1,0. A maioria das bactérias necessita de uma $a_{w}$ de 0,9 para desenvolvimento. Quando o alimento é desidratado a $a_{w}$ diminui para em torno de 0,65 a 0,75 dificultando o crescimento microbiano e aumentando a validade comercial. No caso da liofilização grande parte dos microrganismos é destruída na fase de congelamento (JAY, 2005). 


\subsubsection{ALTA PRESSÃO}

Altas pressões são aplicadas por um tempo pré-determinado em pacotes de alimentos submersos em um líquido. A pressão é distribuída de maneira uniforme e instantânea. A alta pressão no alimento leva a morte celular; pressões mais moderadas podem levar à inativação celular (FELLOWS, 2006).

$\mathrm{Na}$ Figura 7 pode-se observar um esquema de funcionamento do aparelho.

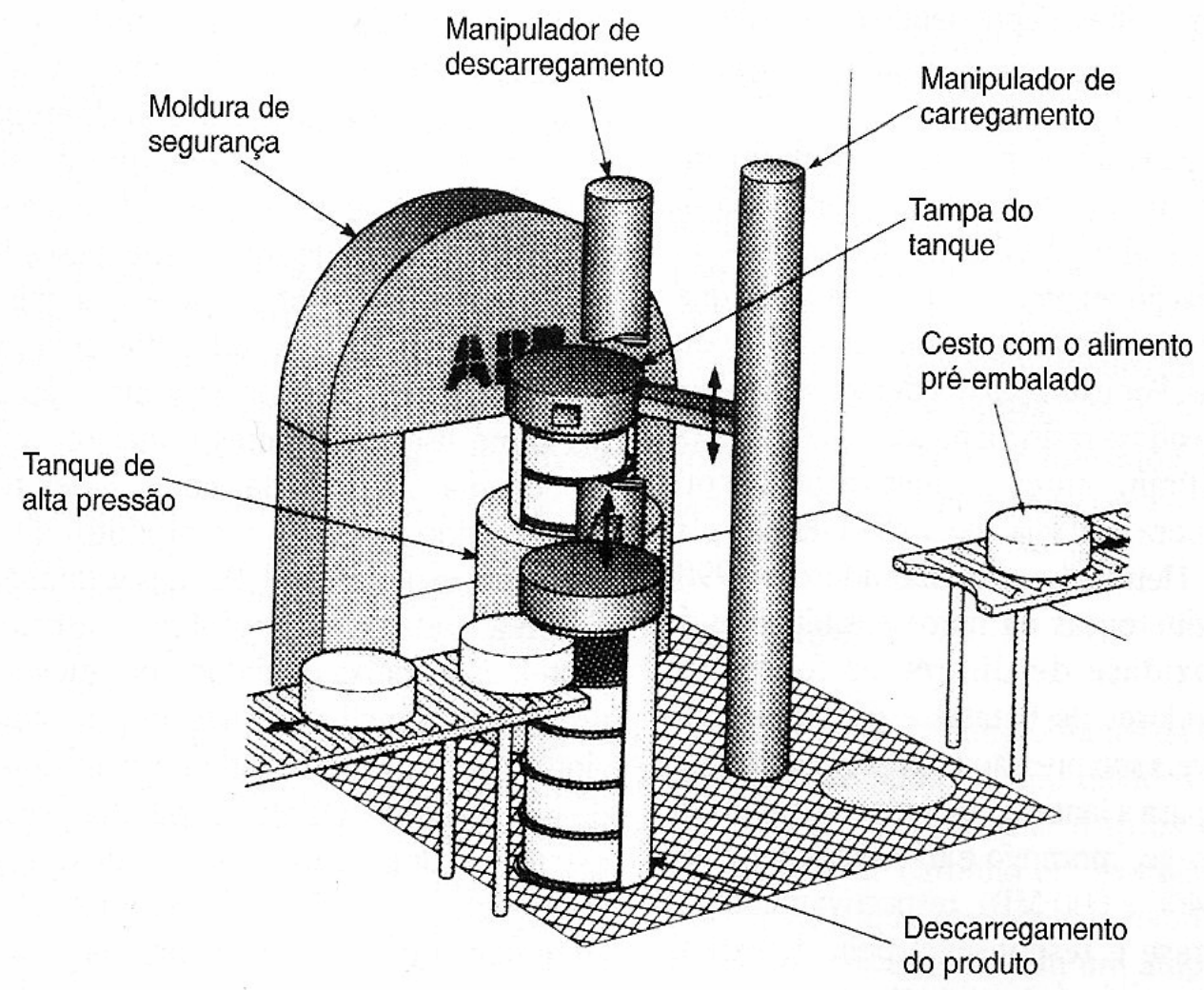

Figura 7: Desenho esquemático de uma unidade produtora por alta pressão. Fonte: Fellows, 2006.

Células vegetativas são inativadas sob alta pressão, sendo as bactérias Gram positivas mais resistentes e a fase estacionária também mais resistente que a log. Quanto à constituição dos alimentos, quanto menor a $a_{w}$ maior é a barorresistência (JAY, 2005). 
Lee e colaboradores (1999) avaliaram o uso do processo de alta pressão como uma alternativa aos métodos já utilizados para ovos líquidos e verificaram que deve ser bem estudadas as condições do processamento, pois este pode ocasionar uma coagulação protéica. Os mesmos autores, anos depois (LEE et al., 2003) determinaram experimentalmente o melhor processo de conservação sobre alta pressão para ovos levando em consideração a inativação microbiana e a coagulação protéica. A inativação microbiana foi analisada pela redução das bactérias Listeria seeligeri e Escherichia coli.

Segundo Juliano e colaboradores (2006) e Aguilar e colaboradores (2007), o processo de alta pressão pode diminuir o poder de gelatinização da gema do ovo.

Juliano (2008) concluiu que a alta pressão em produtos pré-cozidos de ovos pode ser usada para ampliar a validade comercial sem substituição ao processamento térmico visando menores alterações sensoriais. Também, associou a alta pressão e altas temperaturas, como $700 \mathrm{MPa}$ e $105^{\circ} \mathrm{C}$ por 5 minutos, podendo ser usadas para a esterilização comercial de produtos de baixa acidez como o ovo. Afirmou, adicionalmente, que quando este processamento é usado para ovo pré-cozido não dispensa o armazenamento do produto em refrigeração. Ainda considerou que a alta pressão incrementa a gelatinização de proteínas pré-coaguladas do ovo, podendo ser um fator benéfico. Por último, constatou em seu experimento que não houve alterações sensoriais significativas para os produtos derivados de ovos pré-cozidos que foram submetidos à alta pressão.

\subsection{CONTROLES}

Segundo Mano et al. (2006), os controles necessários na industrialização de ovos são:

- A qualidade da matéria-prima e do produto final;

- Na etapa da quebra: temperatura da sala, higiene dos equipamentos (Ponto Crítico - PC); 
- Na pasteurização: binômio tempo e temperatura;

- Na embalagem: contaminação pós-processamento (PC);

- Estocagem.

\section{CONCLUSÃO}

O ovo possui grande importância não apenas na alimentação como também no processamento de alimentos e desenvolvimento de produtos por suas características funcionais. Portanto, a indústria de ovos prosperou em tecnologia de conservação para atender ao mercado. Os produtos derivados de ovos representam uma grande parcela da produção industrial.

O estudo e implantação dessas técnicas foram essenciais para ampliar o uso de ovos na indústria alimentícia. Permitiu-se, assim, liberdade de formulações, economia em transporte, menores perdas com quebras, melhor conservação do produto aumentando o prazo comercial e o fornecimento de um produto de qualidade tecnológica e sanitária.

A pasteurização, desidratação e tecnologias emergentes como a alta pressão, são grandes aliadas à fabricação industrial e uniformização dos produtos, sendo atualmente o maior mercado consumidor. Porém, técnicas emergentes na indústria de ovos devem ser melhores estudadas para ser considerada como um processamento de sucesso e seja produzido em escala comercial disponibilizando estas vantagens e segurança não somente à indústria, mas também nos supermercados, ao alcance do consumidor.

\section{REFERENCIAS BIBLIOGRÁFICAS}

AGUILAR, J.M.; CORDOBÉS, F.; JEREZ, A.; GUERRERO, A. Influence of high pressure processing on the linear viscoelastic properties of egg yolk dispersions. Rheologica Acta. Heidelberg: Springer Berlin, v. 46, n. 5, p. 731-740, maio, 2007

AVISITE. Disponível em: <http://www.avisite.com.br>. Acesso em: abr. 2009.

BERGQUIST, D.H. Egg desydration. In: STADELMAN, W.J.; COTTERILL, O.J. (Ed.). Egg science and tecnology. 4. ed. Nova York: Food Products Press, 1995. 591 p. cap. 14, p. 335-376. 
BRASIL. Ministério da Agricultura, Pecuária e Abastecimento. Departamento de Inspeção de Produtos de Origem Animal (DIPOA). Decreto Lei no 30.691, de 29 de março de 1.952. Alterado pelos Decretos no 1.255 de 25/06/62, no 1.236 de 02/09/94, no 1.812 de 08/02/96, no 2.244 de 04/06/97 e. no 6385, de 27/02/2008 Regulamento da Inspeção Industrial $e$ Sanitária de Produtos de Origem Animal (RIISPOA). Brasília: RIISPOA, 2008.

BRASIL. Portaria no 01, de 21 de fevereiro de 1990. Ministério da Agricultura, Pecuária e Abastecimento. Secretaria de Defesa Agropecuária. Divisão de Inspeção de Carnes e Derivados - DICAR. Normas Gerais de Inspeção de Ovos e Derivados. Diário Oficial [da] República Federativa do Brasil, Brasília, DF, n.44, p. 4321, 6 de mar. 1990. Seção 1.

CARVALHO, J.C.A.P. Avaliação de parâmetros da pasteurização de ovos em casca, considerando a destruição da Salmonella Enteritidis. Niterói, 2005. 157f. Tese (Doutorado em Higiene Veterinária e Processamento Tecnológico de Produtos de Origem Animal) Universidade Federal Fluminense, 2005.

CUNNINGHAM, F.E. Egg-Product Pasteurization. In: STADELMAN, W.J., COTTERILL, O.J. Egg Science and Technology. 4. ed. Binghamton: New York, 1995. cap. 12, p. 289-321.

ESCARABAJAL, C.; TENUTA FILHO, A. Estabilidade oxidativa do colesterol em ovo integral em pó. Revista Brasileira de Ciências Farmacêuticas. São Paulo: Divisão de Biblioteca e Documentação do Conjunto das Químicas da Universidade de São Paulo, vol. 41, n. 4, p. 483490, out./dez., 2005.

FELLOWS, P. J. Tecnologia do processamento de alimentos: princípios e práticas. Porto Alegre: Artmed, 2006.

GLOBAL AGRISYSTEM. Disponível em: <http://mpstateagro.nic.in/Project\%20Repo

JAY, J.M. Microbiologia de alimentos. 6. ed. Porto Alegre: Artmed, 2005. 712p.

JULIANO, P. High pressure thermal sterilization of egg products. Washington, 2006. $204 \mathrm{f}$. Tese (Doctor of Philosophy) - Department of Biological Systems Engineering, Washington State University, Washington, 2006.

JULIANO, P.; LI, B.; CLARK, S.; MATHEWS, J.W.; DUNNE, P.C.; BARBOSA-CÁNOVAS, G.V. Descriptive analysis of precooked egg products after high-pressure processing combined with low and high temperatures. Journal of Food Quality, San Francisco: Wiley, v. 29, p. 505-530, 2006.

KATUIIN-RAIEM, B; MIHALJEVIC, B.; RAIEM, D. Time-Dependent Postirradiation Oxidative Chemical Changes in Dehydrated Egg Products. Journal of Agricultural and Food Chemistry. Washington: ACS, v.40, p.1946-1952, 1992.

KIJOWSKI, J.; LESNIEROWSKI, G.; ZABIELSKI, J.; FISZER, W.; MAGNUSKI, T. Radiation pasteurization of fronzen whole eggs. In: SIM, J.S.; NAKAI, S. (Ed.). Egg uses and processing technologies. Oxon: Cab International, 1994. 436 p. pt. 4, cap. 28, p. 340-348.

LEE, D.U.; HEINZ, V.; KNORR, D. Effects of combination treatments of nisin and high-intensity ultrasound with high pressure on the microbial inactivation in liquid whole egg. Innovative Food Science and Emerging Technologies. Berlin: Elsevier, v.4, p. 387-393, 2003.

LEE, D.U.; HEINZ, V.; KNORR, D. Evaluation of Processing Criteria for the High Pressure Treatment of Liquid Whole Egg: Rheological Study. Innovative Food Science and Emerging Technologies. Berlin: Elsevier, v.32, p. 299-304, 1999. 
MAGGI. E. Huevos e Derivados. Disponível em: <http://www.alimentosargentinos.gov.ar/03/revistas/r_42/cadenas/Carnes_Huevos_derivados .htm>. Acesso em: abr. 2009.

MANO, S.B.; FANTICELLI, R.; QUEIROZ, M.; PARDI, H. Tópicos em tecnologia de ovos e derivados. Niterói: Universidade Federal Fluminense, 2006. 29p.

NATUROVOS. Disponível em: <www.naturovos.com.br>. Acesso em: abr. 2009.

ORDÓÑEZ, J.A.; RODRÍGUEZ, M.I.C.; ÁLVAREZ, L.F.; SANZ, M.L.G.; MINGUILLÓN, G.D.G.F.; PERALES, L.H.; CORTECERO, M.D.S. Tecnologia de alimentos: componentes dos alimentos e processos. Porto Alegre: Artmed, 2005a. v.1.

ORDÓÑEZ, J.A.; RODRÍGUEZ, M.I.C.; ÁLVAREZ, L.F.; SANZ, M.L.G.; MINGUILLÓN, G.D.G.F.; PERALES, L.H.; CORTECERO, M.D.S. Tecnologia de alimentos: alimentos de origem animal. Porto Alegre: Artmed, 2005b. v.2.

ORMENESE, R.C.S.C.; MISUMI, L.; ZAMBRANO, F.; FARIA, E.V. INFLUÊNCIA DO USO DE OVO LÍQUIDO PASTEURIZADO $E$ OVO DESIDRATADO NAS CARACTERÍSTICAS DA MASSA ALIMENTÍCIA. Ciência e Tecnologia de Alimentos. Campinas: Sociedade Brasileira de Ciência e Tecnologia de Alimentos, v. 24, n. 2, p. 255-260, abr.-jun. 2004.

OVOVITA. Disponível em: <http://www.ovovita.pl/>. Acesso em: abr. 2009.

RODRIGUES, K.R.M.; SALAY, E. Atitudes de granjeiros, atacadistas, varejistas e consumidores em relação à qualidade sanitária do ovo de galinha in natura. Revista de Nutrição, v.14, n.3, p.185-193, 2001.

SHUMAN, J.D.; SHELDON, B.W.; VANDEPOPULIERE, J.M.; BALL, H.R. Immersion heat treatments for inativation of Salmonella Enteritidis with intact eggs. Journal of Applied Microbiology, v. 83, p. 438-444. 1997. 